\title{
ANÁLISE COMPARATIVA DE EDITORIAIS NOS JORNAIS FOLHA DE S.PAULO E ESTADO DE S. PAULO
}

\section{COMPARATIVE ANALYSIS OF EDITORIALS IN THE NEWSPAPERS FOLHA DE S.PAULO AND ESTADO DE S. PAULO}

Verônica Mendes de Oliveira ${ }^{1}$ Universidade de Taubaté (Unitau)

\section{RESUMO}

Esta pesquisa analisa o discurso ideológico de editoriais publicados nos jornais Folha de S.Paulo e O Estado de S. Paulo em 2018. Pretende-se verificar de que forma cada veículo expressa sua opinião por meio dos editoriais, considerando as marcas linguísticas e as abordagens adotadas. A partir daí, espera-se relacionar esse posicionamento à linha ideológica e aos interesses mercadológicos de cada veículo. Para realizar este trabalho, tomou-se como base as teorias de gêneros discursivos de Bakhtin (2003), além de estudos acerca da análise de editoriais. O corpus utilizado foi composto por quatro editoriais publicados no mês de setembro de 2018 e a análise foi dividida em pares, de acordo com o tema abordado nos textos. Espera-se que esse trabalho possa contribuir para ressaltar a importância de uma leitura crítica de exemplares desse gênero, de maneira que o leitor considere também as implicações externas relativas ao texto.

PALAVRAS-CHAVE: Editorial; jornal; gênero discursivo.

\begin{abstract}
This research analyzes the ideological discourse of editorials published in the newspapers Folha de S.Paulo and O Estado de S. Paulo in 2018. It is intended to verify how each vehicle expresses its opinion through the editorials, considering the linguistic and the approaches adopted. It is also expected to relate this position to the ideological line and the market interests of each vehicle. In order to carry out this work, the theories of discursive genres of Bakhtin (2003), as well as studies about the analysis of editorials were taken as base. The corpus was composed of four editorials published in the month of September 2018 and the analysis was divided into pairs, according to the topic addressed in the texts. It is hoped that this work may contribute to emphasize the importance of a critical reading of this genre, so that the reader also considers the external implications related to the text.
\end{abstract}

KEYWORDS: Editorial; journal; discursive genre.

\section{INTRODUÇÃO}

Esta pesquisa visa analisar as marcas discursivas e ideológicas presentes em quatro editoriais publicados nos jornais Folha de S.Paulo e O Estado de S. Paulo em 2018. Para tanto, considerouse que o gênero editorial se destaca por seu caráter jornalístico e, portanto, presente no cotidiano dos cidadãos em geral. Além disso, diferentemente de outros gêneros dessa esfera, este apresenta não apenas a informatividade como também um posicionamento representativo da ideologia do jornal que o publica.

Dessa forma, o objetivo desta pesquisa é verificar de que forma o jornal expressa sua opinião por meio dos editoriais, considerando as marcas linguísticas e as abordagens adotadas nesses textos. A partir daí, pretende-se relacionar esse posicionamento à linha ideológica e aos

${ }^{1}$ Mestre em Linguística Aplicada pela Universidade de Taubaté (SP). E-mail: veronicamendes@outlook.com. 
interesses mercadológicos de cada veículo. Com base nisso, espera-se que esse trabalho possa contribuir também para ressaltar a importância de uma leitura crítica de exemplares desse gênero, dada a necessidade, por parte do leitor, de identificar os implícitos presentes no discurso que traduzem interesses mercadológicos e ideológicos do veículo midiático.

A escolha dos jornais Folha de S.Paulo e O Estado de S. Paulo justifica-se pela sua ampla circulação no país. Segundo pesquisa do IVC Brasil (Instituto Verificador de Comunicação), em março de 2019, a Folha foi a líder de circulação total entre os jornais brasileiros em março, com 332.415 exemplares diários (considerando circulação digital e impressa). O jornal carioca O Globo veio em segundo lugar, com 319.785, e O Estado de S. Paulo, em terceiro, com 245.022 exemplares. Já na Grande São Paulo, Folha e Estadão são os líderes em número de leitores da versão impressa, tendo a primeira 1,4 milhão de leitores e o segundo, pouco mais de 1 milhão.(FOLHA, 2019).

Ademais, levou-se em consideração o fato desses dois jornais possuírem, tradicionalmente, posturas ideológicas distintas: A Folha é considerada, pelo senso comum, como mais "centrista", enquanto o Estado é visto como mais "conservador". (OLIVEIRA, 2004, p.102).

Para realizar esse trabalho, foi selecionado um corpus composto de quatro editoriais publicados no mês de setembro de 2018 - dois deles na Folha de S.Paulo e outros dois no Estado de S. Paulo. Os textos foram disponibilizados nos sites dos referidos jornais. A análise foi dividida em pares, de acordo com o tema abordado nos editoriais, para verificar de que forma cada veículo se posicionou em relação a um mesmo assunto.

Para tanto, foi considerada a Análise Dialógica do Discurso proposta pelo círculo de Bakhtin (2003), bem como estudos específicos do gênero editorial, tendo em vista as especificidades do gênero e o contexto histórico e sociocultural em que os textos se inserem, bem como as possíveis motivações de seus autores - no caso, os jornais diante do referido contexto. Assim, foram destacadas marcas linguísticas, a escolha do vocabulário e a seleção das informações que sustentam a argumentação (como estatísticas e referências históricas).

\section{Fundamentação teórica}

\section{$1.1 O$ gênero editorial}

Com base na proposta de Bakhtin (2003), considera-se, inicialmente, que os gêneros do discurso são tipos relativamente estáveis de enunciados, inseridos nas práticas sociais. Destaca-se, de antemão, que todos os enunciados produzidos (sejam eles verbais ou escritos) dialogam, de alguma forma, com enunciados anteriores. Da mesma forma, o enunciado abre espaço para respostas futuras, que podem ser imediatas ou aparecerem tempos depois. Assim, tem-se uma cadeia discursiva: um enunciado oferece uma resposta a outro precedente e, simultaneamente, pressupõe uma nova resposta vinda de um interlocutor futuro. É nesse contexto que se apoia o conceito de dialogismo.

Assim, pode-se considerar que a comunicação (verbal ou não verbal) sempre será dialógica, uma vez que o enunciatário - isto é, aquele que "recebe" o enunciado - sempre responderá ao que foi dito. Essa resposta pode ser verbal, gestual, falada, escrita ou até mesmo interna (caso o enunciatário não a expresse publicamente, embora reflita sobre ela), mas certamente ela será produzida. Sempre haverá algum tipo de interação entre enunciatário e enunciado.

Ainda segundo essa teoria, toda forma de comunicação é um enunciado. Cada enunciado, por sua vez, é único e não se repete, uma vez que, mesmo sendo idêntico a outro, ele reflete a individualidade de seu enunciador. Simultaneamente, o enunciado depende também do interlocutor, porque é ele quem oferece completude a essa relação, com seu ato responsivo.

Nesse sentido, cada gênero seria caracterizado por, pelo menos, três dimensões: o conteúdo temático (as informações trazidas pelo enunciado), a forma composicional (a estrutura que o texto adota para atender às finalidades comunicativas) e o estilo (as configurações discursivas, linguísticas e textuais). $\mathrm{O}$ atendimento a essas três esferas, de forma sistematizada, promoveria a configuração 
de um enunciado em um determinado gênero - por esse motivo, diz-se que os gêneros são "relativamente estáveis", cumprindo diferentes funções comunicacionais:

\begin{abstract}
Em cada campo existem e são empregados gêneros que correspondem às condições específicas de dado campo; é a esses gêneros que correspondem determinados estilos. Uma determinada função (científica, técnica, publicística, oficial, cotidiana) e determinadas condições de comunicação discursiva, específicas de cada campo, geram determinados gêneros, isto é, determinados tipos de enunciados estilísticos, temáticos e composicionais relativamente estáveis. (BAKHTIN, 2003, p.266)
\end{abstract}

Pode-se ainda considerar que a língua é carregada de ideologias, uma vez que ela acompanha as evoluções sociais. Conforme a forma de reação dos indivíduos diante do enunciado muda, seus valores passam a ser outros e isso se reflete na linguagem, evidenciando seu caráter dialógico. Nesse sentido, o discurso carrega não só as marcas verbais deixadas no enunciado, como também marcas da enunciação de um sujeito e seu contexto. É preciso analisar esse contexto, portanto, para que o enunciado seja plenamente compreendido.

A partir dessa questão do contexto, destaca-se que o diálogo, para Bakhtin, acontece em todo tipo de comunicação (verbal ou não, face a face ou não), não se limitando apenas à alternância de vozes face a face - denominada como gênero do discurso primário. Esse gênero primário se caracteriza pelas comunicações verbais espontâneas, ou seja, o diálogo imediato. Nesse caso, a linguagem oral já carrega consigo o contexto comunicacional. O gênero secundário, por outro lado, apresenta uma situação comunicacional mais complexa, principalmente na modalidade escrita.

Quando escreve, o autor possui um interlocutor em mente, mesmo que este não seja um indivíduo em específico. Esse interlocutor é denominado leitor presumido e com ele o autor estabelece relações dialógicas. $\mathrm{Na}$ linguagem escrita, porém, essas relações acontecem de forma distinta da interação face a face, afinal, não há um diálogo espontâneo - ou seja, não é possível que o leitor converse de imediato com o autor e saiba exatamente no que ele estava pensando quando redigiu o texto. Dessa forma, como já referido, é preciso que haja no texto uma contextualização prévia desse enunciado para que o interlocutor possa compreendê-lo.

Baseado na teoria bakhtiniana, Alves Filho (2006) afirma que os editoriais constituem, efetivamente, um gênero discursivo. Isso porque eles possuem relativa estabilidade no que tange a estilo, tema e forma composicional. Além disso, eles fazem parte de uma esfera social de comunicação - a atividade jornalística - e, neste contexto, permitem a alternância entre os sujeitos envolvidos - o jornal e seus leitores. Por fim, os editoriais possuem também uma autoria préconfigurada, caracterizada por Alves Filho como "autoria institucional", ou seja, sustentada pelo jornal como um todo (e não assinada por um profissional em específico, como no artigo de opinião, por exemplo). as seguintes:

Em relação às características constituintes do gênero editorial, Alves Filho (2006) enumera

a) Impessoalização - o texto é narrado não em primeira pessoa do singular, mas em terceira pessoa, assim como em boa parte dos gêneros jornalísticos. Ou seja, apesar de seu caráter opinativo, o editorial exprime marcas linguísticas que se aproximam da impessoalidade e objetividade;

b) Institucionalização - o texto representa uma instituição ou empresa, a qual assume a responsabilidade pelo ponto de vista expresso;

c) A ausência de assinatura individual;

d) Uso da variedade padrão de linguagem;

e) Interação entre a instituição e os indivíduos leitores;

f) Coerência enunciativa - o ponto de vista expresso pelo editorial deve estar de acordo com a linha ideológica sustentada pelo veículo;

g) Ineditismo - em geral, cada exemplar de editorial é publicado uma única vez e em um único jornal. 
Dentre essas características, Zavam (2009) destaca a questão da institucionalização, isto é, da representatividade da "opinião da empresa". A autora aponta que há, invariavelmente, interesses financeiros atrelados a defesa de determinado ponto de vista:

[...] desde que o jornalismo virou atividade comercial, fonte de lucro e consequentemente de poder, o editorial deixou de representar a voz do dono e passou a representar a defesa de interesses de setores empresariais e financeiros. Continua sendo expressão de opinião, mas a opinião das forças que os mantêm. (ZAVAM, 2009, p. 131)

Destaca-se também o caráter argumentativo do gênero editorial. Koch e Elias (2016) pontuam que a argumentação está intrinsecamente associada ao uso da linguagem, isto é, a argumentatividade é parte estruturante de todo e qualquer discurso, mediando, nesse sentido, as interações sociais. Assim, mesmo os textos que, à primeira vista, são considerados "neutros" contêm em si uma ideologia.

Essa ideologia, por sua vez, é fruto das experiências individuais e concepções de mundo do autor do texto - o sujeito argumentante. Ao almejar convencer ou persuadir seu interlocutor pelo discurso, esse sujeito seleciona estratégias argumentativas que sustentam seu ponto de vista (que se expressa de forma explícita ou implícita no discurso), visando influenciar decisões, valores e posicionamentos do interlocutor. Nas palavras de Koch e Elias (2016, p. 24), portanto, a argumentação pode ser definida como "o resultado textual de uma combinação entre diferentes componentes, que exige do sujeito que argumenta construir, de um ponto de vista racional, uma explicação, recorrendo a experiências individuais e sociais, num quadro espacial e temporal de uma situação com finalidade persuasiva".

Dentre os componentes mencionados pelas autoras, destacam-se as estratégias argumentativas que constituem o conteúdo textual e objetivam a sustentação e a defesa do ponto de vista do autor. Apresentação de fatos, declarações de terceiros, estabelecimento de intertextualidade, questionamentos e comparações são alguns dos elementos que podem ser empregados no texto argumentativo - e comumente nos editoriais - com a finalidade de convencer, persuadir ou influenciar o leitor.

Nesse sentido, ao se analisar o discurso de opinião contido no editorial, verifica-se a necessidade de associá-lo também à visão de mundo e aos valores sustentados pelo veículo de informação que o publica. Esses valores caracterizam a chamada linha ideológica do jornal, ou seja, a ideologia que o veículo defende tradicionalmente, expresso, por vezes, em documentos divulgados ao público, como no caso da Folha de S.Paulo e do Estado de S. Paulo.

\subsection{A Folha de S.Paulo}

Conforme sua página na internet, o jornal Folha de S.Paulo é mantido pelo conglomerado brasileiro Grupo Folha, que mantém também portais de notícias, o instituto de pesquisa Datafolha, uma editora, uma agência de notícias, gráficas e transportadoras. O grupo iniciou suas atividades em 1921, em São Paulo, com o jornal "Folha da Noite". Posteriormente, surgiram a "Folha da Manhã" (1925) e "Folha da Tarde" (1949). Em 1960, as três publicações se fundiram na Folha de S. Paulo.

Organizada em cadernos temáticos diários e suplementos, atualmente a Folha circula em todo o território nacional. Ainda segundo seu site, o veículo foi o primeiro no Brasil a adotar a figura do ombudsman e a oferecer conteúdo on-line.

\subsubsection{Perfil do público}

Com base em pesquisa feita pelo IBOPE em 2017, a Folha divulgou o perfil de seu público na grande São Paulo (região em que o jornal é editado). De acordo com esses dados, dos 1.731 .000 leitores da versão impressa do jornal, 53\% são do sexo feminino. Quanto à classe econômica, 28\% 
dos leitores classificam-se como classe A, 25\% como classe B e 40\% como classe C. As faixas etárias com maior participação são dos 25 a 34 anos (20\%) e dos 35 a 44 anos (19\%).
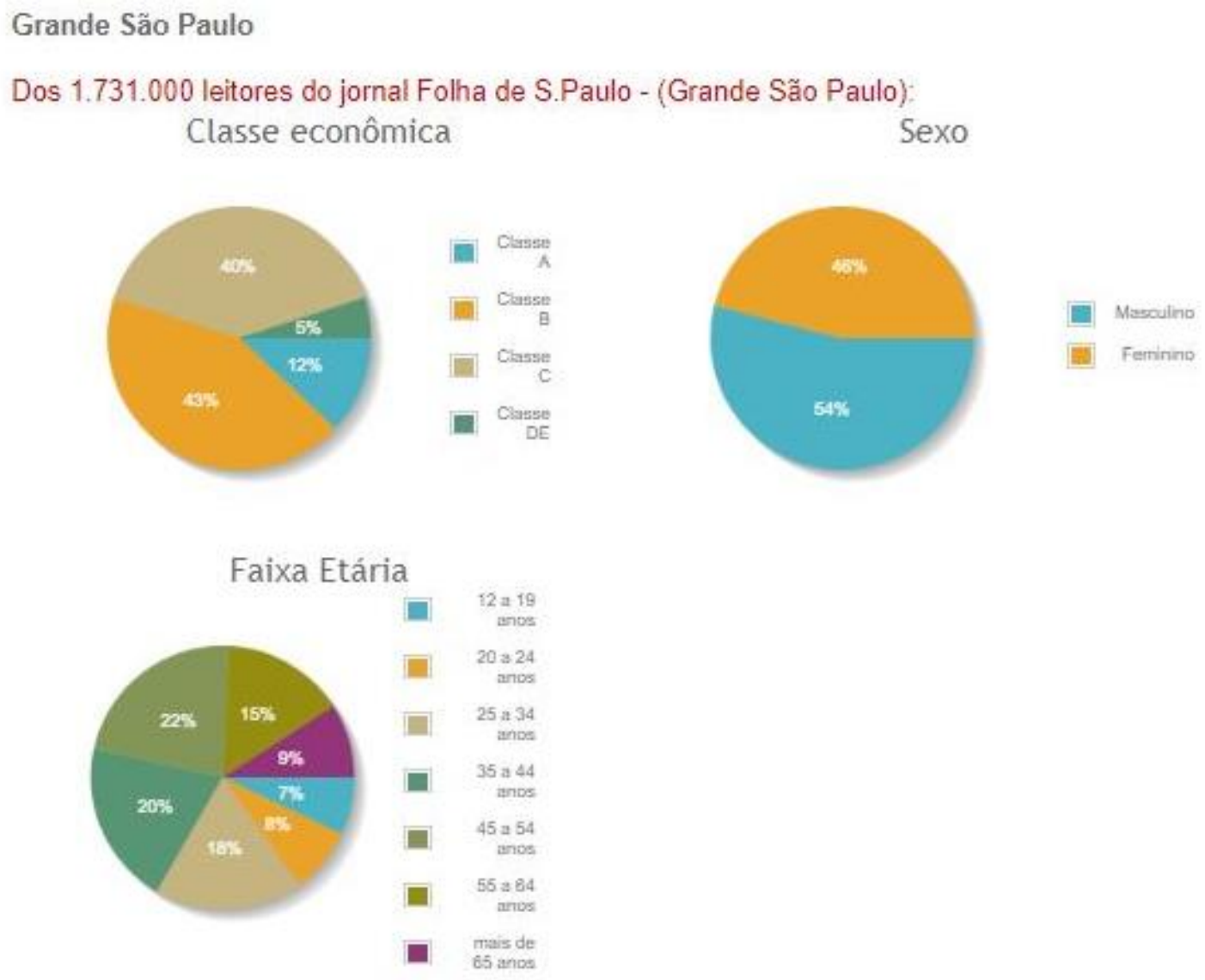

Figura 1: Gráfico de perfil dos leitores da Folha de S.Paulo (FOLHA DE S.PAULO, 2018)

\subsubsection{Linha editorial e ideológica}

Desde 1981, a Folha elabora projetos editoriais para nortear o trabalho dos profissionais da empresa. O documento original passou por reestruturações ao longo do tempo, que buscaram adequá-lo conforme o contexto sociopolítico. Na primeira versão desse projeto, a Folha define sua premissa como "um jornalismo crítico, apartidário e pluralista". Entretanto, recentemente, o jornal alega que suas atividades não devem se resumir a esses três ideais, posto que, como a imparcialidade total é mera utopia, a mídia deve, também, defender suas próprias convicções.

É necessário que o jornal, sem discriminar opiniões diversas das que adota (e, ao contrário, estimulando polêmicas com elas), tenha as suas próprias convicções sobre os fatos e os problemas. Elas é que transformam o jornal em um ser ativo, com uma identidade visível e um certo papel a desempenhar. (FOLHA DE S.PAULO)

Nesse sentido, a Folha defende, em seu mais recente projeto editorial (datado de 2017), o pluralismo e o debate de ideias como meio de proporcionar reflexões acerca de temáticas em âmbito nacional e global. Isto é, ao apresentar opiniões diversas sobre um mesmo assunto, o veículo espera contribuir para ampliar as perspectivas críticas de seus leitores. Contudo, isso não invalida a importância de uma apuração precisa dos fatos.

Praticar o pluralismo não significa abrir mão da apuração factual, mas entender que, muitas vezes, existe uma dimensão sujeita a controvérsia, a ser contemplada em termos de dosagem, perspectiva e proporção. A diversidade se manifesta também no amplo espectro ideológico do corpo de colunistas, que abriga as correntes de opinião mais 
representativas da sociedade e faz da Folha um desaguadouro natural de ideias e posições em conflito. (FOLHA DE S.PAULO)

Por fim, mesmo diante do pluralismo de opiniões, o jornal volta a ressaltar a relevância de se defender seu próprio ponto de vista: "O fato de contar com um espectro denso e variado de opiniões assinadas não exime o jornal de emitir a sua própria sobre os temas mais relevantes, mas as posições que assume não tutelam a cobertura noticiosa.” (FOLHA DE S.PAULO).

De fato, analisando o teor de suas publicações ao longo do tempo, percebe-se que a Folha se posicionou contrária a sucessivos governos, desde Geisel até Temer, independentemente do viés político ("direita" ou "esquerda"). Como exemplo, destaca-se o ocorrido na época do governo Collor, quando o editor Otávio Frias Filho e outros três profissionais do jornal foram processados pelo presidente, sob acusação de irregularidades na cobrança de anunciantes. (FOLHA, 2016). Pouco tempo depois, o jornal sugeriu abertamente o impeachment do governante. Mais recentemente, em 2009, a Folha divulgou uma suposta ficha policial de Dilma Rousseff, na época pré-candidata à presidência. Após ser alvo de críticas, o jornal fez uma retratação afirmando que "não pode ser assegurada bem como não pode ser descartada" a veracidade do documento divulgado. (FOLHA, 2009)

\subsection{O Estado de S. Paulo}

Conforme consta em seu site, o Estado de S. Paulo (popularmente conhecido como Estadão) foi fundado em 1875, com o título "A Província de S. Paulo", ainda sob o regime monárquico. O jornal só adotou o nome atual em 1890, com a consolidação da República. A publicação considera-se "pioneira em venda avulsa no país" - isso porque, no início de suas atividades, o Estado implantou um novo sistema de distribuição, com um divulgador saindo a cavalo pelas ruas e anunciando as notícias do dia. Posteriormente, a silhueta do divulgador tornou-se parte do logotipo do jornal.

Ao longo do tempo, o jornal criou diferentes serviços, formando, assim, o Grupo Estado - composto, além da publicação impressa, por portais on-line, agências de notícias e rádios. Atualmente, possui também uma versão digital, que pode ser acessada por computador e dispositivos móveis. (O ESTADO DE S. PAULO).

\subsubsection{Perfil do público}

Segundo pesquisa do instituto Ipsos em 2013, o Estadão considera seu total semanal de leitores na Grande São Paulo (região em que o jornal é editado) como estimado em 1.016.000. Desses, $56 \%$ são do sexo masculino. $21 \%$ pertencem à classe $\mathrm{A}, 59 \%$ à classe $\mathrm{B}$ e $19 \%$ à classe $\mathrm{C}$. As faixas etárias com maior participação são dos 25 a 34 anos (22\%) e dos 35 a 44 anos (21\%). 

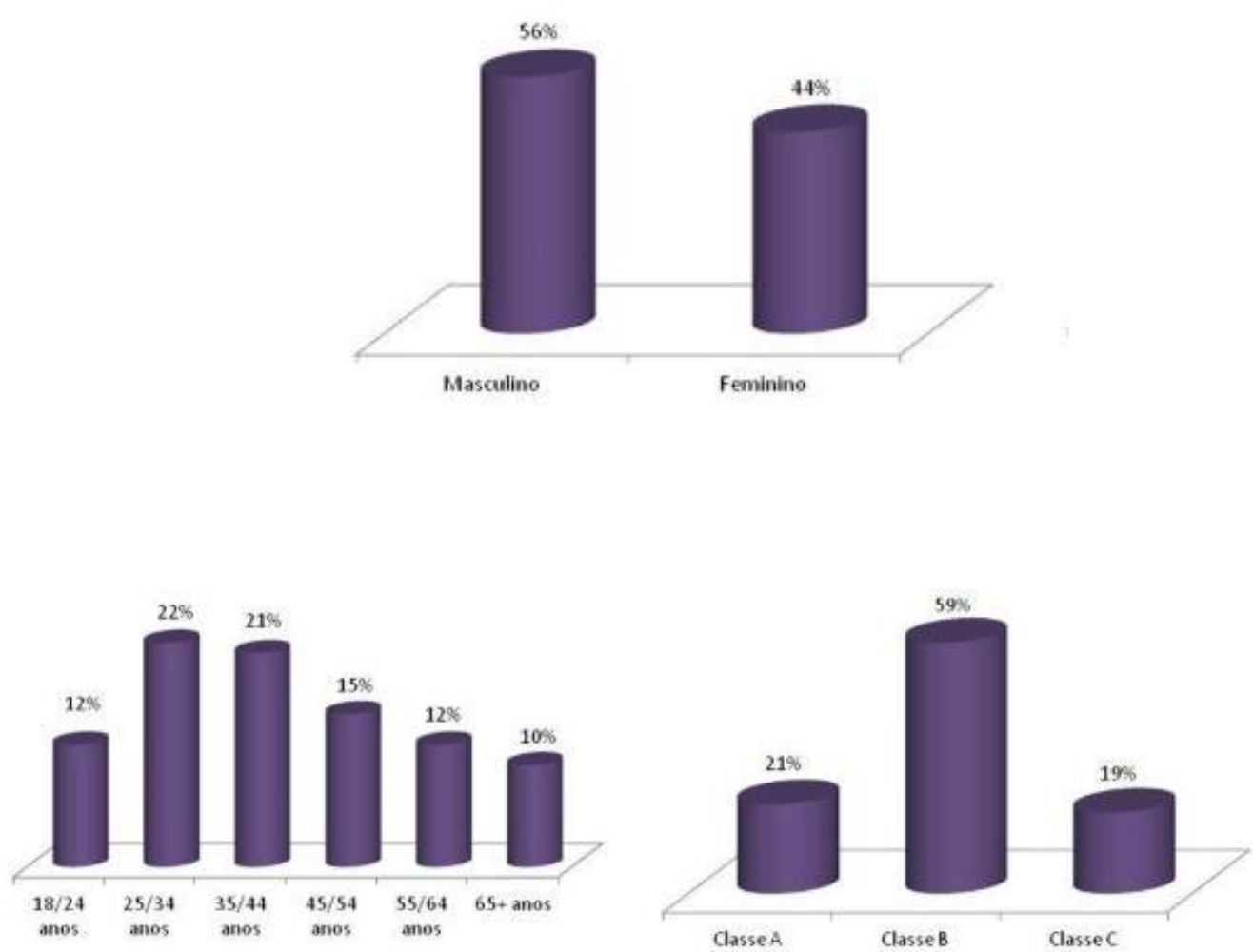

Figura 2: Gráfico de perfil dos leitores do Estado de S. Paulo (O ESTADO DE S. PAULO, 2018)

\subsubsection{Linha editorial e ideológica}

Em seu código de ética, disponibilizado no site do jornal, o Estado declara defender "o sistema democrático de governo, a livre iniciativa, a economia de mercado e um Estado comprometido com um país economicamente forte e socialmente justo" (O ESTADO DE S. PAULO). Dentre suas missões editoriais, estão o compromisso com a democracia, com a liberdade de expressão e de imprensa e com a justiça, estando, portanto, alinhado com os valores promovidos pela Declaração Universal dos Direitos do Homem.

Assim como a Folha, o Estado, mediante o documento que define a Linha Editorial do Grupo Estado, afirma defender o pluralismo e a liberdade de opiniões, estando "aberto ao debate dos assuntos públicos, independentemente de suas posições editoriais". Apesar disso, o jornal alega que não compactua com teses que neguem a liberdade ou a dignidade do cidadão. (O ESTADO DE S. PAULO).

O jornal afirma que "nasceu com princípios republicanos e abolicionistas", adotando, portanto, uma posição liberal perante à monarquia. Segundo Guilherme (2018), após a proclamação da República, o jornal passou a apoiar a república oligárquica e a ideologia positivista. Já na década de 1930, durante o governo Vargas, o Estado posicionava-se contra o comunismo, classificando-o como "ameaça à estrutura social do país". A partir daí, o periódico passou a adotar uma linha ideológica conservadora e contrária a ideais populistas, em diferentes épocas, tecendo críticas expressivas aos governos JK, João Goulart e Lula:

O compartilhamento de valores ideológicos que converteu o Estadão em aliado da UDN, dos militares e de Collor, o faz hoje aliado do PSDB e do governo Michel Temer. É possível afirmar que o jornal sempre se colocou contra as pautas progressistas, estejam elas simbolizadas por Vargas, Jango, Lula ou qualquer outro político, movimento social 
ou partido de esquerda. Os mesmos eixos temáticos de ameaça populista e corrupção foram usados de forma sistemática para pressionar e desestabilizar os governos Vargas, Jango, Lula e Dilma. (GUILHERME, 2018, p. 220)

\section{Metodologia de pesquisa}

A fim de verificar de que forma o discurso ideológico se constitui no gênero editorial nos jornais Folha e Estadão, foi selecionado para análise um corpus constituído por quatro exemplares do gênero. Os textos estão disponíveis nos sites dos jornais escolhidos.

O corpus no qual essa análise se baseia é constituído por quatro editoriais publicados nos jornais supracitados em de setembro de 2018: "Museu de cinzas" (Folha de S. Paulo), "Os donos do incêndio" (O Estado de S. Paulo), "Após a facada" (Folha de S. Paulo) e "Defesa eloquente da democracia" (O Estado de S. Paulo). A análise foi dividida em pares, de modo que cada par de editoriais versa sobre um mesmo tema: o incêndio no Museu Nacional, no Rio de Janeiro, e o atentado ao então candidato à presidência da República Jair Bolsonaro.

Com base nesse material, verificou-se de que forma cada veículo se posicionou em relação a um mesmo assunto. Para tanto, considerou-se as marcas linguísticas utilizadas e a abordagem adotada, isto é, quais aspectos foram destacados pelo autor texto para discorrer sobre os fatos. Por fim, observou-se a articulação entre esses fatores e a linha ideológica e editorial de cada jornal, bem como possíveis interesses mercadológicos.

\section{Análise comparativa de editoriais}

\section{1 "Museu de cinzas" e "Os donos do incêndio"}

Os dois editoriais analisados neste tópico comentam sobre o incêndio no Museu Nacional no Rio de Janeiro. O primeiro texto foi publicado pela Folha no dia 4 de setembro de 2018. Já o texto do Estadão foi veiculado no dia seguinte. Ambos lamentam o ocorrido e indicam a falta de recursos repassados ao museu como um dos fatores causadores do sinistro. Os textos, porém, apresentam diferentes visões sobre o fato.

O editorial da Folha intitula-se "Museu de cinzas" e foi publicado no site do veículo no dia 4 de setembro de 2018, sob o cabeçalho "O que a Folha pensa: Texto não assinado que expressa a opinião da Folha" - um demonstrativo prévio de que o texto apresentará um ponto de vista assinado pela equipe do jornal. Abaixo do título e do subtítulo, há uma foto em preto e branco, ocupando toda a tela de rolagem. Na imagem, vê-se o Museu Nacional no Rio de Janeiro em chamas, observado pela população, em primeiro plano.

O texto tem início logo após a foto, considerando que o descaso com o museu provém de má-gestão há gerações. Em seguida, ressalta-se o prejuízo material acarretado pelo incêndio, enumerando itens do acervo destruídos pelo fogo:

\footnotetext{
Além de uma das maiores coleções de arqueologia clássica da América Latina, perdemse milhões de itens centrais para a identidade nacional e a história natural do país. Lá se encontravam, por exemplo, o crânio de Luzia (...) e um conjunto etnológico inestimável. (...) Estima-se que tenham sido dizimados testemunhos de centenas de povos indígenas, muitos já desaparecidos. Pereceram também vários holótipos, os espécimes originais que serviram para a descrição científica de espécies da flora e da fauna brasileiras. (FOLHA DE S.PAULO, 2018)
}

Afirma-se ainda que houve um corte de recursos destinados ao museu, ligado à UFRJ; além disso, há um desinteresse geral na manutenção da instituição. Não são apontados "culpados" pelo ocorrido, ao contrário, durante todo o texto, define-se que ele é fruto de um descaso há muito tempo instaurado e merecia maior atenção por parte da comunidade científica. 
(...) não há dúvida de que houve corte de recursos para o museu, ligado à Universidade Federal do Rio de Janeiro. Entretanto a má alocação do dinheiro público é problema muito mais amplo e antigo - ao qual a comunidade científica deveria dedicar atenção maior. (FOLHA DE S.PAULO, 2018)

O editorial do Estado, por sua vez, foi publicado no site na madrugada do dia 5 de setembro de 2018. O gênero do texto é destacado por um cabeçalho fixo no alto da página, onde se lê "Opinião". O texto focaliza os possíveis "culpados" pelo problema, ideia expressa desde o título: "Os donos do incêndio". Esse ponto de vista é corroborado logo no primeiro parágrafo, quando o texto afirma ser necessário "tentar entender as causas e as devidas responsabilidades" relacionadas à tragédia com o museu.

Não há fotos ou menções ao acervo perdido. Diferentemente da Folha, o Estado afirma (com base em estatísticas sem fonte) que não houve corte de recursos para a instituição - pelo contrário, a verba aumentou. No entanto, houve má gestão desse montante, administrado pela UFRJ, instituição mantenedora do museu. O jornal ainda isenta o Governo Federal de responsabilidade pelo ocorrido.

Houve quem tenha se apressado em culpar o ajuste fiscal do governo Temer pelas más condições do Museu Nacional. No entanto, não existe tal relação de causa e efeito. Por exemplo, entre 2014 e 2017, houve um aumento dos recursos da União destinados à UFRJ. Em 2014, a universidade recebeu R \$ 2,6 bilhões. Em 2017, foram R \$ 3,1 bilhões. O problema é que, nesse período, o valor gasto pela UFRJ com pagamento de pessoal saltou de $\mathrm{R} \$ 2,1$ bilhões para $\mathrm{R} \$ 2,6$ bilhões. O aumento de $\mathrm{R} \$ 500$ milhões foi para o funcionalismo. (O ESTADO DE S. PAULO, 2018)

Em seguida, o editorial concentra-se em relacionar o sinistro ao descaso da administração atual da UFRJ, ressaltando que ela possui integrantes alinhados a partidos de esquerda (PSOL e PCdoB) - que, na opinião do jornal, defendem "uma ideologia excludente" e "avessa ao diálogo".

O reitor da UFRJ, Roberto Leher, é filiado ao PSOL. A vice-reitora, Denise Fernandes Lopez Nascimento, também é filiada ao PSOL (...). Há também outros dois pró-reitores filiados ao PCdoB (...). É um acinte que a administração da maior universidade federal do País seja controlada por dois partidos políticos que, como se sabe, difundem uma ideologia excludente, avessa ao diálogo e tantas vezes inimiga das liberdades e garantias fundamentais. Só num ambiente de pluralismo e de respeito à liberdade de pensamento e de expressão é que a universidade pode cumprir sua relevante função social. (O ESTADO DE S. PAULO, 2018, grifo nosso)

Ainda nesse trecho, destaca-se o uso da expressão "como se sabe" ao caracterizar os dois partidos políticos, como se as características atribuídas a eles não fossem mera visão subjetiva do jornal, mas um conhecimento de senso comum. Isto é, as marcas linguísticas dão a entender que a caracterização descrita não é uma opinião apenas do jornal, mas da população em geral.

\section{2 "Após a facada" e "Defesa eloquente da democracia"}

Os editoriais analisados neste tópico foram publicados no dia 11 de setembro de 2018, sendo o primeiro veiculado pela Folha e o segundo, pelo Estado. Ambos têm como tema central o cenário pré-eleições presidenciais, logo após o atentado ao então candidato Jair Bolsonaro, esfaqueado durante um comício em Juiz de Fora (MG), no dia 6 de setembro (FOLHA DE S.PAULO, 2018). Os dois textos avaliam o ocorrido de forma negativa (a Folha considerou o atentado "abominável", e o Estado, "um crime gravíssimo") e, a partir dele, analisam o cenário préeleições. No entanto, novamente, as abordagens apresentam significativas distinções.

Mais uma vez, o editorial da Folha abre com o cabeçalho "O que a Folha pensa: Texto não assinado que expressa a opinião da Folha". Abaixo do título "Após a facada" (Anexo C), há uma fotomontagem com os candidatos mais bem colocados nas pesquisas eleitorais até então: Ciro 
Gomes (PDT), Fernando Haddad (PT), Jair Bolsonaro (PSL), Geraldo Alckmin (PSDB) e Marina Silva (Rede).

O texto se atém a dados fornecidos pelo próprio Datafolha (instituto de pesquisas estatísticas mantido pelo próprio Grupo Folha, também responsável pelo jornal) para atualizar o panorama das intenções de voto. Primeiramente, o editorial faz menção ao início da propaganda eleitoral e ao veto à candidatura de Lula à presidência, para, então, referir-se ao atentado a Bolsonaro. Afirma-se que o atentado não representou impactos significativos nesse cenário, pois, com base nas pesquisas do Datafolha, apesar de Bolsonaro liderar as pesquisas para o primeiro turno até então, ele não superaria nenhum concorrente no segundo turno - previsão que não se concretizaria ao fim das eleições, com a vitória do candidato do PSL.

(...) consolida-se a liderança de Bolsonaro, que oscilou de $22 \%$ no levantamento anterior, de 21 e 22 de agosto, para 24\%. (...) Não por acaso, Bolsonaro não supera nenhum concorrente nas simulações de segundo turno. Embora tenha oscilado positivamente, a variação, dentro da margem de erro, sugere que o impacto eleitoral da violência sofrida pelo capitão reformado não foi intenso como muitos chegaram a supor. (FOLHA DE S. PAULO, 2018)

Em seguida, o editorial apresenta os percentuais de intenções de voto a cada um dos candidatos retratados na fotomontagem. Não há críticas explícitas a um ou outro presidenciável; apenas comentários baseados nas estatísticas. Nesse trecho, o texto mais se assemelha a uma reportagem do que a um texto opinativo. Por fim, o jornal prevê uma nova investida dos presidenciáveis contra Bolsonaro após o atentado: "Em tal cenário, é de imaginar que chegará rapidamente ao fim a trégua concedida pelos adversários a Bolsonaro após o abominável esfaqueamento da semana passada." (FOLHA DE S. PAULO, 2018)

Por outro lado, tem-se o texto do Estadão, denominado "Defesa eloquente da democracia" (Anexo D). O editorial parte do episódio do atentado para defender uma "campanha eleitoral pacífica e civilizada".

Embora a Folha avalie que o cenário de intenções de voto após o atentado a Bolsonaro não tenha sofrido grandes impactos, para o Estado, o ocorrido foi significativo para o clima relativamente respeitoso instaurado no debate entre presidenciáveis (realizado pelo próprio jornal, em parceria com a TV Gazeta) - isto é, antes do incidente, a atuação dos candidatos teria se mostrado mais ferrenha.

A reação dos outros candidatos à Presidência da República ante o atentado contra o deputado Jair Bolsonaro, de repúdio à violência e de reafirmação da confiança no processo eleitoral, foi uma importante demonstração de que, apesar de todas as dificuldades e extremismos dos tempos atuais, a democracia segue sendo um valor inegociável. (O ESTADO DE S. PAULO, 2018)

O Estado avalia positivamente esse clima, alegando que ele é essencial para a consolidação da democracia, regime no qual opiniões podem divergir, mas não deixam de ser dignas de respeito. O jornal ainda afirma que o embate de ideias é comum na política, mas deve sempre se pautar na liberdade de expressão e pensamento, sem ferir os direitos dos demais participantes do processo.

É parte da política o embate de opiniões e visões de mundo diferentes. Deve ser sempre, no entanto, um embate respeitoso, com o reconhecimento de que o adversário político tem os mesmos direitos de expressão e a mesma liberdade de pensamento. (O ESTADO DE S. PAULO, 2018)

A partir dessa ideia, o jornal defende também o "respeito às regras do processo eleitoral", condenando, com base nisso, a tentativa de candidatura de Lula, que havia sido preso meses antes, e o discurso de "vitória antecipada" de Bolsonaro, que afirmou que seria eleito, a menos que houvesse fraude nas urnas.

Atenta contra a democracia quem tenta, por exemplo, burlar a legislação eleitoral em benefício próprio, como vem ocorrendo com o sr. Lula da Silva. No caso, além de desejar 
passar por cima da Lei da Ficha Limpa, o PT promove um insidioso discurso contra as instituições (...)

Não é democrático que um candidato diga que não acatará outro desfecho que não seja a sua vitória. Dias antes do atentado ocorrido em Juiz de Fora, o deputado Jair Bolsonaro afirmou que, "desde que não haja fraude nas eleições, ele será eleito presidente". O candidato (...) ainda disse que "qualquer que seja o lado perdedor, não vai reconhecer" (O ESTADO DE S. PAULO, 2018)

O trecho parece se deslocar da tese do editorial, que era a defesa do clima respeitoso entre os presidenciáveis, evidenciado no debate. $\mathrm{O}$ texto parte dessa premissa para tecer críticas a dois dos candidatos - que, curiosamente, nem participaram da mencionada sabatina.

O editorial prossegue com a opinião do General do Exército Eduardo Villas Bôas acerca dos efeitos políticos do atentado a Bolsonaro, retomando uma entrevista do general ao próprio jornal. Não fica claro o porquê de ter sido reproduzida a fala de um militar e não de um especialista em ciências políticas, por exemplo.

"O atentado (contra o deputado Jair Bolsonaro) confirma que estamos construindo dificuldade para que o novo governo tenha uma estabilidade, para a sua governabilidade, e podendo até mesmo ter sua legitimidade contestada. Por exemplo, com relação a Bolsonaro, ele não sendo eleito, ele pode dizer que prejudicaram a campanha dele", disse o general Villas Bôas. (O ESTADO DE S. PAULO, 2018)

Enfim, tem-se o trecho final do texto:

Foi alvissareiro que o primeiro debate entre os presidenciáveis após o atentado de Juiz de Fora tenha sido com mais propostas e menos agressões pessoais. É com respeito à lei e ao eleitor, com ideias e sem violência, que a democracia pode superar os obstáculos que continuamente tentam lhe criar. (O ESTADO DE S. PAULO, 2018)

Assim, o editorial termina retomando sua tese inicial, retomando a defesa de um debate respeitoso, em defesa "da lei e do eleitor".

\section{Resultados}

Com base na análise comparativa dos quatro editoriais, percebe-se que os jornais Folha e Estado partiram de um mesmo tema para desenvolver abordagens distintas. Embora a própria Folha reconheça não ser totalmente imparcial, seu posicionamento foi mais brando - isto é, não houve críticas explícitas a uma instituição ou a um candidato em específico.

Ademais, o jornal teceu uma contextualização dos fatos, nos dois casos - ao abordar o acervo perdido no museu e o cenário da disputa eleitoral, por exemplo -, antes de apresentar sua opinião. Há, ainda, o uso de estatísticas (embora fornecidas pelo próprio Datafolha, mantido pelo Grupo Folha, também responsável pelo jornal) como base para a argumentação.

Já o Estadão partiu dos fatos para apresentar críticas explícitas a ideologias de esquerda (associando o incêndio ao museu aos administradores ligados ao PSOL e PCdoB e afirmando que a candidatura de Lula é uma afronta à democracia) e ao discurso de Bolsonaro. O jornal justifica essas opiniões com base na defesa da democracia e da gestão pública eficiente. No entanto, isso corrobora sua tendência conservadora e avessa ao populismo. Na visão de Guilherme (2018, p. 22), ao tomar tal posicionamento, o jornal "recomenda o voto em políticos à direita e destrata as alternativas de esquerda", como se "a posição neoliberal do jornal fosse natural e não lhe coubesse críticas ou debates" - o que vai contra a defesa do pluralismo, um dos fatores ressaltados em sua Linha Editorial.

Contudo, curiosamente, dadas as intensas mudanças no cenário político do Brasil nas últimas eleições, no editorial "Defesa eloquente da democracia", o Estadão também teceu críticas a um candidato conservador, Jair Bolsonaro, cujo discurso de "não aceitar outro resultado para as eleições que não fosse sua vitória" foi caracterizado pelo jornal como "não democrático". Destaca- 
se, porém, o uso do trecho de uma entrevista concedida por um militar (e não um especialista em política) para sustentar a argumentação do texto, cuja temática é de cunho político.

\section{CONSIDERAÇÕES FINAIS}

A análise dos dados desta pesquisa mostrou que, no gênero editorial, é possível perceber, mais claramente do que em outros gêneros jornalísticos, a linha ideológica defendida pelo veículo de informação (no caso, os dois jornais analisados). Isso se deve ao fato de que o editorial apresenta, entre suas características principais, a defesa de um ponto de vista, alinhado à visão de mundo sustentada pelo veículo.

Nesse sentido, entende-se que diversos fatores podem justificar a defesa de um ou outro posicionamento pelo jornal - sobretudo, critérios mercadológicos e econômicos, baseados em seu público leitor. Se o jornalismo totalmente imparcial é mera utopia, conforme a própria Folha de S.Paulo (2017) pontua em seu projeto editorial, é possível que o veículo adote a postura que melhor lhe convém diante do cenário sociopolítico do país, levando em consideração o perfil majoritário de seus leitores. Em outras palavras, o jornal "diz aquilo que seu público quer ouvir" para poder continuar vendendo seus exemplares.

Isso se verifica, por exemplo, no caso do alinhamento do Estadão com os setores da elite conservadora - que compõe, hoje, a maior parte de seu público leitor -, em diferentes períodos históricos (desde seu favorecimento às elites oligárquicas durante a República Velha, passando pelas críticas ao comunismo no Governo Vargas e, mais recentemente, ao populismo dos governos do PT. Segundo Guilherme (2018),

\footnotetext{
O Estadão conhece o seu público leitor e escreve no objetivo de dirigi-lo. O jornal destacase como porta-voz dos interesses empresariais, especialmente da burguesia paulista representada pela FIESP. Porém “na 'guerra de trincheiras', em que o jornal se encontra envolvido, a classe média seria um posto avançado" (FONSECA, 2005, p. 192), a base da democracia brasileira, celeiro de líderes para espraiar a ideologia neoliberal. (GUILHERME, 2018, p. 220)
}

Diante dessa realidade, fica clara a necessidade de se desenvolver uma leitura crítica diante desse gênero discursivo. É preciso que o leitor identifique no editorial as marcas ideológicas sustentadas pelo jornal, distinguindo aquilo que é descrição de fatos da opinião subjetiva promovida pelo veículo. Ademais, torna-se necessário articular tais opiniões com fatores externos que justifiquem esse posicionamento, isto é, é preciso indagar quais motivos levaram o jornal a defender tal ponto de vista.

Sob essa visão, destaca-se, sobretudo, a importância na formação de leitores críticos, que sejam capazes de detectar a ideologia predominante no texto lido, ainda que implícita, bem como suas motivações. Dessa maneira, esse leitor poderá avaliar os argumentos com quais teve contato para, então, construir seu próprio ponto de vista acerca do cenário social, político e cultural do país.

\section{REFERÊNCIAS BIBLIOGRÁFICAS}

ALVES FILHO, Francisco. A autoria institucional nos editoriais de jornais. Alfa, São Paulo, v. 50, n.1, p. 77-89, 2006. Disponível em: <https://periodicos.fclar.unesp.br/ alfa/article/view/1396/1096>. Acesso em: 26 nov. 2018.

BAKHTIN, Mikhail. Os gêneros do discurso. In: Estética da comunicação verbal. São Paulo: Martins Fontes, 2003.

FOLHA DE S.PAULO. Após a facada. 2018. Disponível em: <https://www1.

folha.uol.com.br/opiniao/2018/09/apos-a-facada.shtml>. Acesso em: 25 set. 2019. 
FOLHA DE S.PAULO. Autenticidade de ficha de Dilma não éprovada. Rio de Janeiro, 2009. Disponível em: <https://www1.folha.uol.com.br/fsp/brasil/ fc2504200915.htm>. Acesso em: 25 set. 2019.

FOLHA DE S.PAULO. Com crescimento digital, Folha lidera circulação total entre jornais brasileiros. 2019. Disponível em: < https://www1.folha.uol.com.br/poder/2019/04/com-crescimento-digitalfolha-lidera-circulacao-total-entre-jornais-brasileiros.shtml>. Acesso em: 25 set. 2019.

FOLHA DE S.PAULO. Folha 95 anos: Da criação do jornal ao futuro digital; veja 9,5 marcos da história da Folha. São Paulo, 2016. Disponível em: <https://www1.folha.uol.com.br/ asmais/2016/02/1744105-da-criacao-do-jornal-ao-futuro-digital-veja-95-marcos-da-historia-dafolha.shtml>. Acesso em: 25 set. 2019.

FOLHA DE S.PAULO. Institucional. Disponível em: < https://www1.folha.uol.com.br/ institucional/>. Acesso em: 25 set. 2019.

FOLHA DE S.PAULO. Linha editorial. 2017. Disponível em: < https://www1.folha. uol.com.br/institucional/linha_editorial.shtml>. Acesso em: 25 set. 2019.

FOLHA DE S.PAULO. Museu de cinzas. 2018. Disponível em: <https://www1. folha.uol.com.br/opiniao/2018/09/museu-de-cinzas.shtml>. Acesso em: 25 set. 2019.

FOLHA DE S.PAULO. Perfil do Leitor. Disponível em: < http://www.publicidade. folha.com.br/folha/perfil_do_leitor.shtml>. Acesso em: 25 set. 2019.

FOLHA DE S.PAULO. Princípios Editoriais: Projeto Editorial. 2019. Disponível em: $<$ http://temas.folha.uol.com.br/folha-projeto-editorial/projeto-editorial-folha-de-spaulo/principios-editoriais.shtml>. Acesso em: 14 out. 2019.

GUILHERME, Cássio. A imprensa como partido político-ideológico: o caso do jornal O Estado de S. Paulo. Dimensões, Vitória, v. 40, p. 199-223, jan./jun. 2018. Disponível em: <www. periodicos.ufes.br/dimensoes/article/download/17905/13828>. Acesso em: 25 set. 2019.

KOCH, I. V.; ELIAS, V. M. Escrever e argumentar. São Paulo: Contexto, 2016.

O ESTADO DE S. PAULO. Defesa eloquente da democracia. 2018. Disponível em: $<$ https://opiniao.estadao.com.br/noticias/geral,defesa-eloquente-da-democracia,70002496422>. Acesso em: 25 set. 2019.

O ESTADO DE S. PAULO. Dados de mercado: Estadão. Disponível em: < http:// publicidade.estadao.com.br/estadao/estadao-dados-de-mercado/>. Acesso em: 25 set. 2019.

O ESTADO DE S. PAULO. Estadão. Disponível em: < http://publicidade.estadao.com.br/ estadao/>. Acesso em: 25 set. 2019.

O ESTADO DE S. PAULO. Grupo Estado: Código de conduta e ética. Disponível em: <https:// www.estadao.com.br/ext/codigoetica/codigo_de_etica_miolo.pdf>. Acesso em: 25 set. 2019.

O ESTADO DE S. PAULO. Os donos do incêndio. 2018. Disponível em: < https://opiniao.estadao. com.br/noticias/geral,os-donos-do-incendio,70002488266>. Acesso em: 25 set. 2019. 
OLIVEIRA, Fabiana Luci de. O Supremo Tribunal Federal no processo de transição democrática: uma análise de conteúdo dos jornais Folha de S.Paulo e Estado de S. Paulo. Revista de Sociologia e Política, Curitiba, n. 22, p. 101-118, jun. 2004. Disponível em: <https://revistas.ufpr.br/rsp/article/view/3664/2921>. Acesso em: 26 out. 2019.

ZAVAM, Aurea Suely. Por uma abordagem diacrônica dos gêneros do discurso à luz da concep̧̧ão de tradição discursiva: um estudo com editoriais de jornal. 2009. 420 f. Tese (Doutorado em Linguística) Universidade Federal do Ceará, Fortaleza, 2009.

Submetido em 24/09/2019

Aceito em 10/02/2020

Publicado em 30/04/2020 